\title{
CELL WALL AND CELL MEMBRANE ANTIGENS USED IN THE CLASSIFICATION OF LACTOBACILLI
}

\section{Elisabeth Sharpe}

National Institute for Research in Dairying Shinfield, Reading, England

\begin{abstract}
Specific antigens occur in many lactobacilli which group them in a similar way to their physiological and genetic characteristics. Thesegroupantigens may be located in the cell membrane or the cell wall, and may be teichoic acids or polysaccharides. Type antigens with a narrower specificity also occur and a ce 11 membrane teichoic acid antigen common to all $1 \mathrm{ac}$ tobacilli and to some other genera has been isolated.

- - - - - - - - -
\end{abstract}

Much work has been done on the classification of lactobacilli using physiological and nutritional tests, (reviewed by Rogosa and Sharpe, 1959), cell wall composition (Ikawa, 1964; Kandler, 1967), esterase patterns (Morichi, Sharpe and Reiter, 1968) and GC ratios (Gasser and Mandel, 1968). It has been possible to relate many of these results to the serological classification of these organisms, and thus to specific antigens they contain. For the serological classification of lactobacilli precipitin techniques using soluble extracts of whole cells or agglutination techniques using whole cells have been used.

Harrison and Opal (1944) used precipitin tests to classify oral and intestinal strains of lactobacilli and found that a soluble carbohydrate antigen could be extracted from the cells and used for serological typing. Sharpe (1955), using acid extracts and specific antisera, classified serologically a collection of 442 strains of lactobacilli of different species and from different sources and divided them by their precipitin reactions into 6 groups, A to $F$ (Sharpe and Wheater, 1957). Many strains were found to possess stable, characteristic antigens which reacted specifically with the antisera. The resultant groupings were similar to those obtained by cultural and biochemical tests. Later work using the other methods of classification mentioned above also confirmed the validity of serological grouping. Since then, Rogosa and Sharpe (1959) have defined a further serological group $G$ which contains strains of L. salivarius. About 70 percent of strains which could be classified physiologically into species reacted with the appropriate antisera. Many lactobacilli therefore possess specific antigens which are characteristic of species.

These group antigens have now been further examined and characterized for 6 of the 7 groups. There is some considerable variation in the location and the chemical nature of the group antigens, some being cell wall, others cell membrane components, and some being teichoic acids and others polysaccharides. 
Cell membrane group antigens

Intracellular teichoic acids are considered to be attached to the protoplast membrane and located in or near the external surface of the membrane (Archibald, Baddiley and Blumson 1968), and are therefore referred to as membrane antigens. In serological group A, Sharpe, Davison and Baddiley (1964) showed that the group antigen was a membrane glycerol teichoic acid with glucosyl residues. A chemically and serologically similar antigen was found in both Lactobacillus helveticus and L. jugurti strains. This gave a reaction of identity with acid extracts of these organisms and reacted specifically with the group A antiserum. In group F, Sharpe et al. (1964) also considered the group antigen to be a membrane glycerol teichoic acid. Knox and Holmwood (1968) have since confirmed that this antigen is located in the membrane.

\section{Cell wall group antigens}

Teichoic acid antigens. Using trichloracetic acid for extraction Sharpe et al. (1964) isolated a teichoic acid from the cell walls of Lactobacillus plantarum and showed that it was a ribitol teichoic acid with mono- and diglucosyl units. Serologically it reacted with specific antisera prepared against group $D$, and showed a reaction of identity to acid extracts of whole organisms of other strains of L. plantarum containing the group D antigen. This work has since been confirmed with another strain of $\mathrm{L}$. plantarum (Davison, pers. comm.). In group $E$, these same workers isolated a teichoic acid from the walls of all four species comprising this group, i.e., L. lactis, L. bulgaricus, L. brevis, and L. buchneri. They found that this was in each case a chemically similar glycerol teichoic acid with glycosyl residues. Serologically these four teichoic acid preparations all reacted with the group E specific antisera, showed a reaction of identity with each other, and also with acid extracts of whole cells of these and other strains belonging to group E.

Polysaccharide antigens. With groups $\mathrm{B}$ and $\mathrm{C}$ much valuable work has been done on the elucidation of the chemical composition of the group antigens by Knox and his co-workers. Knox and Brandsen (1962) showed that the serological specificity of group B was in the polysaccharide component of the wall antigens. By autolytic enzyme degradation of the walls of a strain of $L$. casei in group B, soluble products were obtained which reacted serologically by precipitin test with group $B$ antiserum. The degree of inhibition of this reaction caused by the addition of monosaccharides to the antiserum was observed. Different chemical fractions were obtained from walls after autolysis; for one component in which the major sugar component was rhamnose, it was shown that rhamnose was very effective in inhibiting the precipitin reaction. Galactose and glucose reactions were also shown to contribute to the serological specificity. Further work was done using strains of $\underline{L}$. casei belonging to serological groups $B$ and $C$, and strains of $L$. casei var. rhamnosus which all belong

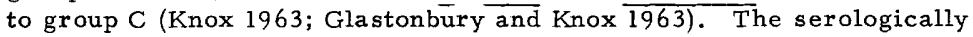
active products were obtained by hydrolyzing cell walls with a preparation of Streptomyces albus muralytic enzyme. Two fractions were obtaine d by precipitation with ammonium sulfate. It was shown that in group B strains, a high content of rhamnose in relation to glucose 
was present in the serologically active fraction. Inhibition of the precipitin reaction by various monosaccharides confirmed that in group $B$, rhamnose is the serologically important component of the group antigen, and the classification of organisms into group B depends on the presence of this sugar. Whilst glucose and galactose contributed to the serological specificity of the first strain examined, they showed no inhibitory effect on precipitation in the two other strains of group $B$ and therefore could not be contributing to their cross reactions.

In group C, strains of L. casei were found to contain only a small amount of rhamnose in the cell wall whilst glucose and galactose were the main components. However, only the glucose was a significant inhibitor of the precipitin test, and therefore mainly responsible for the serological specificity. However, strains of $\underline{L}$. casei var rhamnosus contained a larger amount of rhamnose. Fractionation of the soluble extract showed that the fraction precipitated by ammonium sulfate (Fraction I) contained most of the rhamnose, and that Fraction II not precipitated by ammonium sulphate - was similar in composition to a similar fraction II from the $\underline{L}$. casei strains. Sharpe (1955) has shown that in serological group C, strains of $\underline{L}$. casei possess a group antigen and that strains of $\underline{L}$. casei var. this group antigen, but in addition have a specific type antigen. It seems therefore that the group antigen is contained in Fraction II and that glucose is the major component, whilst the type antigen is contained in Fraction $I$ and rhamnose is the specific determinant.

These results confirmed the serological grouping established by Sharpe (1955), and further work by Glastonbury and Knox (1963) on a collection of 35 i solates physiologically identified as $\underline{L}$. casei and $\underline{L}$. casei var. rhamnosus showed the same serological and chemical specificity, i.e. rhamnose was specifically concerned with the group B antigen, glucose was specific for group $C$ and rhamnose was specific for the type antigen of $L$. casei var. rhamnosus.

To investigate these polys ccharides further, Knox and Hall (1965a) then isolated a number of oligo- and disaccharides from the products of mild hydrolysis of the specific substance (contained in Fraction II) from a group $C$ strain of $\mathrm{L}$. casei. It was found that the component sugars of these oligo-saccharides were glucose, glucosamine, galactose, and galactosamine. The different oligosaccharides were related to each other and inhibited the precipitin reaction to different degrees. Serological specificity probably depended on a glucosyl residue joined by a $\beta \rightarrow 6$ linkage to the adjacent sugar; it was found that $O-\beta-D$-glucopyranosyl $1 \rightarrow 6$ galactose was an effective inhibitor of the precipitin reaction, whilst tri- and tetrasaccharides containing this disaccharide were even more effective. Thus it appears that glucose and galactose are both important components of the cell wall polysaccharide of strains of $\underline{L}$. casei group $\mathrm{C}$.

In further work these authors (Hall and Knox, 1965) studied the linkage between the polysaccharide and mucopeptide components of the cell wall of strains of $\underline{L}$. casei groups $B$ and $C$, and $\underline{L}$. casei var. rhamnosus. Mild acid hydrolysis was sufficient to hydrolyse the linkage in the wall and yield soluble polysaccharides without detectable hydrolysis of the mucopeptide. The release of polysaccharide was accompanied by the hydrolysis of an $\mathrm{N}$-acetylhexosaminide linkage, as a terminal reducing $\mathrm{N}$-acetylhexosamine was then detected. Heating of 
soluble wall products also resulted in the rapid appearance of terminal reducing $\mathrm{N}$-acetylhexosamine due to hydrolysis of the linkage between polysaccharide and mucopeptide. From the rate of chromagen formation from the $\mathrm{N}$-acetylhexosamine it was concluded that the $\mathrm{N}$-acetylhexosamine was substituted on the $C(3)$ position by the adjacent sugar. It was possible to obtain such $\mathrm{N}$-acetylhexosamine residues from both group $B$ and group $C$ strains. However in the rhamose-containing type of specific polysaccharide from L. casei var. rhamnosus no terminal $\mathrm{C}(3)$ substituted $\mathrm{N}$-acetylhexosamine was found.

As the rate of release of the terminal reducing group of the polysaccharide on prolonged acid hydrolysis was comparable to the rate of hydrolysis of glucose 1 - phosphate, this suggested that the polysaccharide and mucopeptide were joined through a phosphate group. A study of the action of phosphatases confirmed this (Knox and Hall, 19.65b); neither wheat germ phosphatase nor oxspleen phosphatase had any detectable effect on purified fractions of polysaccharide or mucopeptide, but both enzymes released 4 percent of the phosphate as inorganic phosphate after the linkage between polysaccharide and mucopeptide components had been hydrolysed by acid. As these enzymes showed activity towards the phosphorylated compound it is probable that the linkage of phosphate to mucopeptide is by a phosphomonoester. Further work confirmed these observations and also showed that in Group B the rhamnose containing group antigen polysaccharide was identified as $\mathrm{L}$ rhamnosyl $(\mathrm{L} \rightarrow 3) \mathrm{N}$-acetyl-D-galatosamine.

Table 1 shows the results so far obtained for the antigenically active chemical constituents of cell walls and membranes of lactobacilli, particularly the different group antigens. The fact that in some species the group antigen is a teichoic acid whereas in others it is a - polysaccharide, is analogous to the streptococci, where in groups $D$ and $\mathrm{N}$ the group antigens are membrane teichoic acids, while in some other groups they are wall polysaccharides.

\section{Type antigens}

Apart from L. casei var. rhamnosus little is known of the type antigens. Serologically many strains of lactobacilli so far examined possess type antigens which are usually strain specific.

One strain of $L$. casei group $B$ examined by Knox and Brandsen (1962) contained 2 different polysaccharides one of which was the group antigen and the other of which contained much more glucose. Serological studies which $I$ have done on this strain have shown the presence of a type specific antigen which may well be this second glucose containing polysaccharide.

However, not all type antigens are polysaccharide. In a strain physiologically identified as L. plantarum, examined by Davison (pers. comm.) an interesting type antigen was observed. This was a teichoic acid, which is unusual for a type antigen, although serologically type specific substances containin teichoic acids have been reported from the capsules of certain pneumonocci (Baddiley 1968). This strain of $\underline{L}$. plantarum did not contain the group D ribitol teichoic acid with glucosyl residues. This teichoic acid differed structurally from other teichoic acids as the glycosyl residues were attached to the 1 (terminal) and not to the 2 position of the glycerol units. I made an antiserum to this organism and tested it agains t extracts of 43 strains of $\mathrm{L}$. plantarum, but 
Table 1. Location and chemical nature of group antigens in different lactobacilii

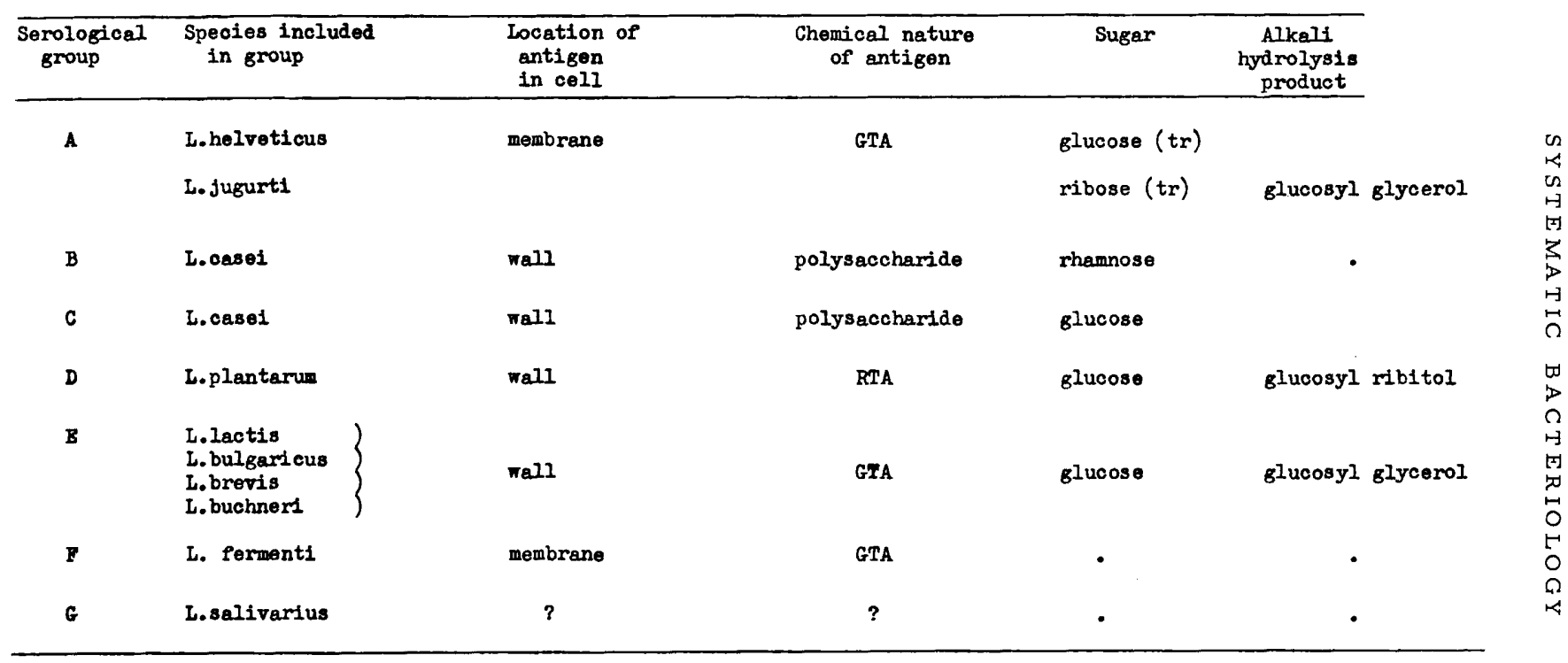

GTA = glycerol telchoic acid

RTA = ribitol teiohoic acid 
Table 2. Serological reactions of antiserum $\mathrm{L}$. acidophilus A22 against $\mathrm{HCl}$ extracts of organisms.

\begin{tabular}{|c|c|c|}
\hline & Genus or Species & \\
\hline & Some species + & \\
\hline Positive & Some species - & Negative \\
\hline Lactobacillus & Pediococcus & Bifidobacterium \\
\hline Staph. aureus & Leuconostoc & Clostridium \\
\hline \multirow[t]{2}{*}{ Sporolactobacillus } & & B. coagulans \\
\hline & & $\begin{array}{l}\text { Group D streptococci } \\
\text { Group N streptococci } \\
\text { *Other serological } \\
\text { groups of streptococci } \\
\text { Esch. coli }\end{array}$ \\
\hline
\end{tabular}

*Grown on a less complex medium.

apart from a few weak cross reactions which could be absorbed out, only the homologous strain reacted with the antiserum, indicating its type specificity. Teichoic acid preparations from the walls of this strain showed a reaction of identity to the acid extract of whole cells, and reacted specifically with this antiserum.

L. acidophilis wall antigens

It has long been thought that the antigenic structure of L. acidophilis is complex and it has not been possible to determine any group antigen. Using acid extracts of 35 strains and precipitin tests, recently $I$ have been able to define 2 groups of $L$. acidophilus each of which possesses its own antigen, and there is a third group for which I could not characterize any antigens. The 10 strains in group I appear to possess 2 antigens, $a$ and $b$, and the 7 group 11 strains to possess 2 antigens, $b$ and $c$, so there is a common antigen between the two. The presence of this common antigen can only be demonstrated to group II antisera and by absorption tests. These antigens were found to occur in the cell wall. Work by Davison (pers. comm.) on these teichoic acids showed that the walls of Group I strain contain a glycerol teichoic acid with no sugar substituent. This preparation reacted with the group I antiserum and gave a reaction of identity with HCI : extracts of other group I strains. It did not however react with group II antiserum, indicating that it was antigen a. Walls of a group II strain contained glycerol teichoic acid, glucose and some galactose; a neutral polysaccharide separated out on paper electrophoresis. This teichoic acid did not react with a group II antiserum, but reacted with a type antiserum to the homologous organism. This was thought to be due to a reaction of the polysaccharide which is probably its type antigen.

It is of interest that Dr. F. Gasser, (pers. comm.) has examined the same collection of strains of $\underline{L}$. acidophilus for their lactic dehydrogenase patterns. He found that 3 different characteristic patterns occurred dividing the species into 3 groups. The se 3 groups correspond to the 2 serological groups and the third serologically unclassified group. There is therefore a good agreement here between 
antigen structure and a biochemical characteristic, in this case possession of a particular enzyme.

\section{Agglutinating antigens}

Using agglutinin absorption, a number of mono-specific antisera have been prepared and used to designate antigens. Williams, Norris and Gyorgy (1953) in a scheme proposed for labelling antigenic components of the genus lactobacillus, divided them into 2 groups: I, homofermentative and II, heterofermentative. Each group was further divided by the occurrence of specific antigens denoted by arabic numbers. This scheme has been generally accepted by workers using agglutinins for antigenic analysis of lactobacilli. So far there are 18 antigens designated in group I and 7 in group II. Some organisms were found to possess more than one of these antigens (Orland, 1950), whilst in L. lactis, the agglutinating antigen appears to be species specific (Miller and Arne Hansen, 1957). In a detailed analysis of the antigens of $\mathrm{L}$. acidophilus, Efthmiou and Arne Hansen (1962) showed that with 25 strains, 6 of the $L$. acidophilus agglutinins could be identified with already identified, previously described,antigens some of which occurred in L. casei, L. casei var. rhamnosus, L. plantarum and other species not named, and 8 new agglutinins were recognized. Many of the strains possessed several antigens.

This method of antigenic analysis shows that although there must be a complexity of surface antigens in strains of lactobacilli, these are not usually species specific and may occur in varying proportions in different strains. So far they have not been investigated chemically, although some work by Williams and Franck (1957) on heterofermenta tive lactobacilli suggests that agglutinating antigens may be polysaccharide. These workers also found that there was no cross reaction between homo- and heterofermentative strains using mono-specific antisera. It appears that the agglutinating antigens are type antigens, which accounts for the large numbers of those already designated and there are obviously others not yet designated. It is useful to know the agglutinating type antigens present, but as the se often cut across species, they can only be used for classification to a limited extent.

Finally, I would like to mention some preliminary results obtained in my laboratory on an antigen common to all lactobacilli and some other species. An antiserum prepared against a strain of $L$. acidophilus was found to react by precipitin test against $\mathrm{HCl}$ extracts of a wide range of organisms, and the reaction was specific in its range. Table 2 shows the results obtained using ring precipitin tests and confirming a reaction of identity with Ochterlony geil diffusion tests.

Some of the se results were confirmed by absorption of the antiserum with different strains of Lactobacilli, leuconostoc, pediococci and Staph. aureus which removed the reaction, and with Group D streptococci and B. coagulans which did not remove it.

This antigen is therefore common to almost all lactobacilli and also occurs in some species of pediococci, leuconostocs and Staph. aureus.

For further investigation of this antigen a strain of $L$. casei group C, used by Knox in his extensive analyses of antigens of tactobacilli, was chosen. $\underline{L}$. casei is known not to contain teichoic acid in the cell wall and we wanted to investigate the location of the antigen which might 
be a teichoic acid. Cell walls were prepared using the Braun homogenizer and washed thoroughly. However, 1) serological activity was observed in the cell sap obtained from the disrupted cells as well as in extracts of the celi wall: 2) heating the washed cell walls at $70^{\circ}$ for $30 \mathrm{~min}$. resulted in some of the antigen being removed from the walls and 3) treatment of the cell walls with trypsin resulted in almost all the activity being lost from the walls. This suggests that the antigen is a membrane component, and that some of the membrane had adhered to the washed cell walls. As the cultures were $48 \mathrm{hrs}$. old possibly the membrane was very adherent.

Separation of this antigen from the group polysaccharide antigen has been achieved by ion-exchange chromatography on DEAE cellulose (Whatman DE52). The group polysaccharide is eluted by the starting buffer (0.02M phosphate, $\mathrm{pH} 6.85)$ and the lactobacillus antigen is then eluted by a sodium chloride gradient at approximately $0.17 \mathrm{M}$. This separation and fractionation was detected by serological testing of the fractions with the $\underline{L}$. acidophilus antiserum, and $\underline{L}$. casei group antiserum. Although a strong serological reaction was obtained for the active fractions the amount of material so far obtained for chemical analysis is only a few milligrams, so that we have not yet been able to determine fully the chemical nature of the antigen. However, my colleague $\mathrm{Mr}$. J. Brock has been able to show by chromatography the presence of organic phosphate, glycerol, alanine and glucose.

This antigen is therefore almost certainly a glycerol teichoic acid. This suggests that the membrane teichoic acid of lactobacilli contains an actively antigenic site which is common to all lactobacilli, some closely related organisms such as pediococci and leuconostocs and also staphylococci. We have not yet been able to do any quantitative work on this antigen but it is apparent that the antiserum we used is extremely potent and can detect very small amounts of antigen.

The antigenic site is either not always exposed or alternately only certain rabbits are sensitive to it, since only 2 out of 6 rabbits inoculated have produced antisera to this antigen; the others produced type sera giving a specific serological reaction with the homologous organism.

This antigen has many similar characteristics to that described by McCarty (1959). Using heat killed group A streptococcal vaccine he raised an antiserum which reacted by precipitin test with $\mathrm{HCl}$ extracts of most haemolytic streptococci, staphylococci, and aerobic spore formers but not Gram-negative bacteria, pneumococci, clostridia, or corynebacteria. Analysis of purified preparations obtained from group A streptococci indicated that the antigen was a simple polymer of glycerophosphate, i.e. a glycerol teichoic acid and was not present in the cell wall. Later work (McCarty 1964) showed that D-alanine was present in ester linkage but was very labile and easily removed. The presence of the $\mathrm{D}$-alanine gave the compound a different antigenic specificity and masked the glycerophosphate reaction. The procedure of $\mathrm{HCl}$ extraction, however, resulted in extraction of the simple glycerophosphat, which reacted with antisera to the polyglycerophosphate antigen.

McCarty's antigen differs from ours in that the specificity is different as the range of organisms possessing this antigen is not the same. Also our antigen isnot a simple glycerophosphate as it appears to contain glycose. However, it is similar in that it occurs in a wide range of organisms, is not species specific, and only occasionally gives rise 
to a potent antiserum - indeed it is only by the fortuitous production of a potent antiserum that these antigens have been detected. It is also similar in that both are probably membrane teichoic acids.

Although such an antigen is not useful in the classification of species of lactobacilli it may be useful in determining relationships at the genus level, once its composition and antigenic determinants are understood.

\section{REFERENCES}

Archibald, A. R., J. Baddiley and N. L. Blumson. 1968. Advances in Enzymology, 30. Ed. F. F. Ford. Interscience Publishers, New York, London, Sidney.

Baddiley, J. 1968. Teichoic acids and the molecular structure of bacterial walls. Proc. Roy. Soc. B. 170:331. and A. L. Davison. 1961. The occurrence and location of teichoic acids in lactobacilli. J. gen. Microbiol. 24:295.

Efthimiou, C. and P. Arne Hansen. 1962. An antigenic analysis of Lactobacillus acidophilus. J. Infect. Dis. 110:258.

Gasser, F. and M. Mandel. 1968. Deoxyribonucleic acid base composition of the genus Lactobacillus. J. Bact. 96:580.

Glastonbury, J. and K. W. Knox. 1963. The serological classification of varieties of Lactobacillus casei. J. gen. Microbiol. $31: 73$.

Harrison, R. W. and Z. Z. Opal. 1944. Comparative studies on lactobacilli isolated from the mouth and intestine. J. dent. Res. 23:1.

Hall, E. A. and K. W. Knox. 1965. Properties of the polysaccharide and mucopeptide components of the cell wall of Lactobacillus casei. Biochem. J. 96:310/

Ikawa, M. 1964. Cell wall composition in relation to the classification of lactic acid bacteria. Taxonomic Biochemistry and Serology. Ed.: C. A. Leone. The Ronald Press Company.

Kandler, O. 1967. Taxonomic and technologische Bedeutung der Gattung Lactobacillus Beijerinck. Zentbl. Bakt. Parisitenk. (Abt. 1. Orig.) Suppl. 2. 139.

Knox, K. W. 1963. Isolation of group specific products from Lactobacillus casei and $\underline{L}$. casei var. rhamnosus. J. gen. Microbiol. 31:59.

and J. Brandsen. 1962. The isolation of components from the cell wall of Lactobacillus casei. Biochem. J. 85:15. and E. A. Hall. 1965a. The isolation of oligosaccharides from cell wall polysacchapide of Lactobacillus casei, serological group C. Biochem. J. 94:525. and - 1965b. The linkage between the polysaccharide and mucopeptide components of the cell wall of Lactobacillus casei. Biochem. J. 96:302. and K. J. Holmwood. 1968. Structure of the cell wall of lactobacilli. Role of muramic acid phosphate in Lactobacillus fermenti. Biochem. J. 108:363.

McCarty, M. 1959. The occurrence of polyglycerophosphate as an antigenic component of various Gram-positive bacterial species. J. Exp. Med. 109:361.

- 1964. The role of D-alanine in the serological specificity of group A streptococcal glycerol teichoic acid. Proc. Nat. Acad. Sci. $\underline{52}: 259$. 
Miller, R. H. and P. Arne Hansen. 1957. Correlation between physiological and serological characters in Lactobacillus lactis. Bac. Proc.

Morichi, T., M. E. Sharpe and B. Reiter, 1968. Esterases and other soluble proteins of some lactic acid bacteria. J. gen Microbiol. 53:405.

Orland, F. J. 1950. A correlation of antigenic characteristics among certain bacteria of the Lactobacillus group. J. infect. Dis. 86:63.

Rogosa, M. and M. E. Sharpe. 1959. An approach to the classification of the lactobacilli. J. appl. Bact. 22:329.

Sharpe, M. E. 1955. A serological classification of lactobacilli. J. gen. Microbiol. 12:107.

A. L. Davison and J. Baddiley. 1964. Teichoic acids and group antigens of lactobacilli. J. gen. Microbiol. 34:333.

and D. M. Wheater. 1957. Lactobacillus helveticus. J. gen. Microbiol. 16:676.

Williams, N. B. and E. B. Franck. 1957. Antigenic analysis of strains of heterofermentative lactobacilli of human oral origin. J. Dent. Res. 36:361.

, R. F. Norris and P. Syorgy. 1953. Antigenic and cultural relationships of Lactobacillus bifidus and Lactobacillus parabifidus. $\mathrm{J}$. infect. Dis. 92:121. 